\title{
Lifetime fitness and age-related female ornament signalling: evidence for survival and fecundity selection in the pied flycatcher
}

\author{
J. POTTI*, D. CANAL* \& D. SERRANO $\dagger$ \\ *Department of Evolutionary Ecology, Estación Biológica de Doñana - CSIC, Seville, Spain \\ $\uparrow$ Department of Conservation Biology, Estación Biológica de Doñana - CSIC, Seville, Spain
}

\author{
Keywords: \\ age-related expression; \\ fecundity; \\ Ficedula hypoleuca; \\ lifetime reproductive success; \\ multistate models; \\ sexual conflict; \\ sexual selection.
}

\begin{abstract}
Ornaments displayed by females have often been denied evolutionary interest due to their frequently reduced expression relative to males, habitually attributed to a genetic correlation between the sexes. We estimated annual and lifetime reproductive success of female pied flycatchers (Ficedula hypoleuca) and applied capture-mark-recapture models to analyse annual survival rates in relation to the patterns of expression (absence/presence) of an ornament displayed by all males and a fraction of females. Overall, the likelihood of expressing the ornament increased nonlinearly with female age and was due to within-individual variation, not to the selective appearance or disappearance of ornament-related expression of phenotypes in the population. Accordingly, expressing the forehead patch in a given year did not influence survival probability. However, those females expressing the ornament at early ages (1-2 years old) enjoyed survival advantages throughout lifetime. Although ornamented females had higher lifetime fecundity and fledging success, their yearly reproductive performance, in terms of fledging productivity, decreased as they aged so that, late in life, ornamented females reared fewer offspring than nonexpressing females of the same age. In addition, both strategies (expressing vs. not expressing the trait) returned similar fitness payoffs in terms of recruited offspring. Our results support the hypothesis that fecundity and survival selection are involved in the displaying of this 'male' ornament by females.
\end{abstract}

\section{Introduction}

Female ornaments (broadly considered as any conspicuous and decorative character displayed by females; Amundsen, 2000a) have frequently been denied evolutionary importance until recently due to their often reduced ('vestigial') expression relative to males, as postulated by the genetic correlation hypothesis of modern days (Lande, 1980, 1987; Cuervo et al., 1996; Amundsen, 2000a,b; Roulin et al., 2001a; Amundsen and Pärn, 2006; Bonduriansky \& Chenoweth, 2009;

Correspondence: Jaime Potti, Department of Evolutionary Ecology, Estación Biológica de Doñana - CSIC, Av. Américo Vespucio s/n, 41092 Seville, Spain.

Tel.: (+34) 954232340 ext. 1402; fax: (+34) 954466700 and (+34) 954621 125; e-mail: jpotti@ebd.csic.es
Potti \& Canal, 2011; Rosvall, 2011; Tobias et al., 2012) which can be traced back to Darwin (1871). Evolutionary theory states that males and females may be displaced from their different phenotypic optima due to sexual genetic conflict, as alleles of the underlying shared genes may be beneficial to one sex but detrimental to the other (Lande, 1980; Clutton-Brock, 2007; Bonduriansky \& Chenoweth, 2009; Bonduriansky, 2011; Mills et al., 2012). Abundant empirical work in the last two decades suggests, however, that in some cases selection may act on male and female traits quite independently, implying no conflict between the genetic correlation and functional explanations of female ornamentation (Amundsen and Pärn, 2006; Kraaijeveld et al., 2007), as theoretically supported by Lande's $(1980,1987)$ models on the evolution of sexual dimorphism (Bonduriansky \& Chenoweth, 2009). 
According to those models, which are supported by recent experimental work (Doutrelant et al., 2012; Simmons \& Emlen, 2008; Morales et al., 2009), attractiveness will at some point become detrimental for females because showiness will be constrained by a trade-off between allocation to fecundity and to female ornamentation (Fitzpatrick et al., 1995). Given directional selection towards greater female showiness, it is expected that only high-quality individuals will afford the more costly expressions of ornaments (Zahavi, 1975).

Although 'quality' is often a difficult concept to be precise about (Wilson \& Nussey, 2009), there is little doubt that it should be closely related, if not synonymous, to measurable aspects of fitness, as condition, survival and short- and long-term (lifetime) reproductive success (Clutton-Brock, 1988; Newton, 1989; Cotton et al., 2004). A substantial body of work has examined the relationships between female ornaments, short-term survival and reproductive success and/or surrogates for individual quality in insects (Simmons \& Emlen, 2008), fish (Berglund et al., 1997; Amundsen \& Forsgren, 2001; Kekäläinen et al., 2010), lizards (Weiss, 2006), birds (Roulin et al., 2001a,b; Jawor et al., 2004; Amundsen and Pärn, 2006; Doutrelant et al., 2008; Gasparini et al., 2009; Martínez-Padilla et al., 2011) and mammals (Robinson et al., 2006; Robinson \& Kruuk, 2007; Ezenwa \& Jolles, 2008; Stockley \& Bro-Jørgensen, 2010), with mixed results. Except for avian plumage colour polymorphisms (reviewed by Roulin, 2004; Brommer et al., 2005), however, only two studies to our knowledge have been able to assess the quantitative genetic basis and lifetime fitness consequences of displaying an ornament common to both sexes (Roulin et al., 1998, 2000, 2010). Roulin et al. studied the variation in lifetime reproductive success (LRS) in relation to plumage spotting. They showed that in Barn Owls, Tyto alba, the plumage ornament (spottiness) is genetically inherited and that both females and males adjust adaptively their offspring sex ratio according to their own ornamentation to maximize offspring survival.

In Iberian populations of pied flycatchers (Ficedula hypoleuca Pallas, 1764), some females express a forehead patch of pale (white or creamy) feathers similar to that all males display, although often smaller (by a half, on average; Potti \& Canal, 2011). Both genetic (Potti, 1993; Potti \& Canal, 2011) and functional (Potti \& Merino, 1996; Morales et al., 2007) hypotheses have been invoked to explain female expression as well as size of the 'male' ornament in these populations. A preference of males for females displaying large forehead patches has been suggested on the basis of the reported assortative mating with respect to trait size (Potti \& Merino, 1996; Potti \& Canal, 2011) and the signalling of their age and parasite (trypanosome)-free condition by ornamented females (Potti \& Merino, 1996) although the possibility that assortative mating may be due to reasons other than mate choice cannot be discarded (Burley, 1983; Roulin, 1999; Kraaijeveld et al., 2007). In addition, as in the congeneric collared flycatcher (Ficedula albicollis; Gustafsson et al., 1995; Qvarnström et al., 2006; de Heij et al., 2011), there is positive directional sexual selection in at least some Iberian populations of pied flycatchers on forehead patch size in males. Males with large forehead patches mate more quickly (Potti $\delta$ Montalvo, 1991a) and sire more extra-pair offspring than males with smaller patches (Canal et al., 2011). Although the magnitude of the cross-sex genetic correlation in trait expression is unknown (all males express the trait, hence there is no variance in male trait expression), once expressed in females there is a strong positive genetic correlation between the sexes in trait size (Potti \& Canal, 2011). This sets the potential for genetic conflict between the sexes to occur (Andrés $\&$ Morrow, 2003; Bonduriansky \& Chenoweth, 2009).

Once assessed the genetic basis of trait size and expression (Potti \& Canal, 2011), a second essential step is to answer one of the questions posed by Rosvall (2011) on the 'enigmatic' evolutionary significance of exaggerated traits in females: Are these traits primarily shaped by fecundity and survival selection? Here, we aim to answer this question by examining the significance of female ornament expression (presence/ absence), that is, whether it may be explained by lifetime fitness advantages in terms of survival and reproductive success and thus may signal individual quality. When treated as a threshold trait (Falconer $\delta$ MacKay, 1996), ornament displaying (as opposed to ornament size) in female pied flycatchers has been shown to retain large amounts of unexplained nonadditive genetic and/or environmental variation, with a low (presumably, autosome-based) heritability (Potti $\delta$ Canal, 2011). Because of the relatively low frequency of ornament expression by females (see Results), that variation renders ornament displaying more suitable than ornament size for dissecting the fitness consequences that developing the trait (to any degree) may have for females. We followed survival and reproductive success from yearly reproductive performance to lifetime fecundity and fledging production until recruitment in relation to the expression of the ornament, so that the short- and long-term benefits and costs accrued from trait expression could be ascertained. As both breeding success and trait expression are age dependent (Lundberg \& Alatalo, 1992; Potti, 1993; Potti \& Merino, 1996; Morales et al., 2007), variation along the ontogeny must be taken into account for a meaningful analysis of its fitness-related variation (Amundsen and Pärn, 2006; Kraaijeveld et al., 2007). In doing so, we try to distinguish within-individual from populationwide effects (van de Pol \& Verhulst, 2006) and then look at the consequences of expressing the ornament at particular ages to highlight some of its likely benefits and costs. 


\section{Materials and methods}

\section{Study system}

We studied a population of pied flycatchers breeding in nest boxes in La Hiruela, about $100 \mathrm{~km}$ north-east of Madrid, central Spain, in the breeding seasons from 1987 to 2005, except 2003. Pied flycatchers are small (c. $12 \mathrm{~g}$ ) trans-Saharan migrants that start to arrive to the study area around the third week of April (Potti \& Montalvo, 1991a). All nests were visited regularly to obtain accurate estimates of breeding date, clutch size and number of fledged young. Most breeding adults were captured during incubation (females) or with a nestbox trap while feeding nestlings (males and females), aged (Potti \& Montalvo, 1991a), marked for individual identification with numbered and colour rings and released. Immigrant birds aged as beyond their first year when first captured were ascribed an age of 2 years on the basis of patterns of age at first reproduction observed in birds of exactly known age (Potti \& Montalvo, 1991b). We recorded a female as lacking a forehead patch even when occasionally she had a few (1-2) white feathers interspersed among the 'normal' (i.e. buffy or greyish) feathers, but they did not form a measurable, continuous plumage patch (cf. Morales et al., 2007). Ornament expression was never used as a criterion for ageing females.

All fledglings were ringed on day 13 of nestling age. Most pied flycatchers mate monogamously, but some males succeed in becoming polygamous (Lundberg $\delta$ Alatalo, 1992; Potti \& Montalvo, 1993; Canal et al., 2012). The pairing status of social mates in all nests was categorized as either monogamous or primary or secondary in the case of bigamous social bonds (Lundberg \& Alatalo, 1992; Potti \& Montalvo, 1993).

\section{Fitness estimation}

To estimate fitness components (i.e. survival, clutch size, numbers of 13-day-old fledglings and recruits), we used all information on each individual in addition to a database summarizing the female life-history data (i.e. longevity and LRS; see Table 1) from the former, longitudinal data set. In the summary database, females would be ascribed to either of two groups (ornamented vs. nonornamented) on the basis of expression, or lack thereof, of the forehead patch at least once in their lifetimes and then fitness components would be compared between both groups. The same approach was used but categorizing females as ornamented or not at early ages (1-2 years old). Yet, for age-dependent trait expression as is the case with the female forehead patch (see Results) - a female's longevity obviously influences her likelihood of being classified as ornamented or not. To solve this sampling problem, we used the longitudinal data set, containing all the records on both annual
Table 1 Raw statistics for measurements of lifetime fitness in nonornamented and ornamented female pied flycatchers. These figures, although pointing to a higher quality of ornamented females, should not be taken at face value for the interpretation of ornament expression-related differences in female fitness components. See Fitness estimation in Methods for further explanation.

\begin{tabular}{|c|c|c|c|c|c|c|c|c|}
\hline & \multicolumn{4}{|c|}{ Nonornamented } & \multicolumn{4}{|c|}{ Ornamented } \\
\hline & Mean & $\mathrm{SD}$ & $n$ & range & Mean & $\mathrm{SD}$ & $n$ & Range \\
\hline $\begin{array}{l}\text { Longevity } \\
\text { (years) }\end{array}$ & 3.31 & 1.18 & 232 & $2-6$ & 4.41 & 1.15 & 113 & $2-6$ \\
\hline $\begin{array}{l}\text { Lifetime } \\
\text { fecundity } \\
\text { (no. eggs) }\end{array}$ & 9.26 & 5.38 & 229 & $3-31$ & 14.97 & 7.65 & 113 & $4-39$ \\
\hline $\begin{array}{l}\text { Lifetime } \\
\text { no. of } \\
\text { fledged } \\
\text { young }\end{array}$ & 5.91 & 4.72 & 232 & 0-22 & 10.29 & 6.01 & 113 & $0-31$ \\
\hline $\begin{array}{l}\text { Lifetime } \\
\text { no. of } \\
\text { recruits }\end{array}$ & 0.69 & 1.03 & 232 & $0-5$ & 1.38 & 1.54 & 113 & $0-8$ \\
\hline
\end{tabular}

female reproductive performance (i.e. clutch size, number of fledglings reared to independence and number of recruits from each breeding attempt) as well as the scores of concurrent (yearly) female ornament expression [0 (absence)/1 (presence)]. These models overcome the problem of circularity caused by lifespan influencing both sampling detectability of trait expression and fitness, with trait expression potentially influencing fitness, by directly testing for influences of ornament expression on yearly reproductive success, independently of female lifespan.

Yearly number of eggs and fledglings were analysed with the entire longitudinal data set. Because of the gap in fieldwork in 2003 and as recruits may postpone their first breeding until the second or, more rarely, third year of life (Potti \& Montalvo, 1991b), all breeding events after the year 1999 were excluded from the analysis of annual recruitment. Lifetime analyses were restricted to the fitness components of all females marked for the first time between 1987 and 1996. This time window allows for the time interval (6 years) needed to ascertain recruitment of females marked as fledglings and their offspring for all cohorts. The few females still alive after 1999 were removed from the lifetime analyses in order not to underestimate their performance throughout life.

Our population has the largest recovery rates for both fledglings and breeding adults (fledglings: 14\%; adult males: 52\%; adult females: 54\%; J. Potti, unpublished data) among those reported across Europe in this wellstudied species (Potti \& Montalvo, 1991b; Lundberg \& Alatalo, 1992; Lehtonen et al., 2009). However, recapture rates were $<1$, that is, alive individuals were not 
recaptured on all sampling occasions, so apparent survival was estimated within a capture-mark-recapture (CMR) framework (Lebreton et al., 1992; see Statistical Analyses below).

\section{Statistical analyses}

Variation with age and annual breeding performance We used random intercept generalized mixed models (GLMMs, Bolker et al., 2008) as implemented in sAs (v. 9.2; SAS Institute Inc., 2008) to first investigate agerelated patterns of forehead patch expression (presence/ absence). Within-individual effects were distinguished from between-individual effects (i.e. selective appearance and disappearance of phenotypes) by modelling age of first and last breeding as fixed covariates conditional on the random effect of female identity (van de Pol \& Verhulst, 2006). As age was influential in patch expression (see Results), it was also introduced as a covariate to ascertain whether expressing the ornament correlated with annual reproductive parameters. We analysed numbers of eggs (Poisson error, log link function), fledglings reared to independence (Poisson error, $\log$ link function) and recruits as breeders (negative binomial error, log link function). We also run similar models accounting for the previous life-history stage as a binomial denominator (fledglings/eggs and recruits/ fledglings) and a logit link function. Both type of models showed similar results but, as we were interested in disentangling the independent effect of each life-history stage, we present along the paper the models corresponding to fledging and recruitment rates (see Tables S1 and S2 for the analyses of raw data). In all models, female identity and breeding year were entered as random terms to account for repeated measures of the same female and possible annual differences in patch expression and breeding performance. Laying date was included as a covariate in the models as it is one of the most important determinants of breeding success and recruitment in pied flycatchers (Potti \& Montalvo, 1991b; Lundberg \& Alatalo, 1992). An association between female ornamentation and productivity could be mediated by territory and/or mate quality, with ornamented females breeding in better territories or being paired with males investing more in their broods than nonornamented females. To account for the potential influence of male quality on reproductive parameters, forehead patch size of the female's social male was introduced as a covariate in early stages of the modelling process. In contrast, male age, another potential predictor of reproductive success, was not included in the models to avoid problems of collinearity due to the strong age-assortative mating reported in this population (Potti, 2000). Regarding territory (nest site) quality, it is unrelated to breeding date or any measured male's secondary sex trait in this population, likely because habitat features are not heterogeneous enough to cause large difference in fitness in our population (Canal et al., 2012). Thus, we think it is unlikely that territory or male quality may cause severe biases in our results. Female pairing status (i.e. monogamous, primary and secondary females of polygamous males) was also explored in these first steps because pairing status was related to another female ornament in the related collared flycatcher (the wing white patch; Hegyi et al., 2006, 2008). However, pairing status, forehead patch size of the female's social male or their interactions with trait expression did not explain any variation in female fitness components (data not shown) and were not further considered. Therefore, starting models for annual breeding performance included the effects of patch expression (presence/absence), female age, and age at first and last breeding on clutch size, number of fledglings and number of recruits.

We started from models including all main effects and relevant interactions and proceeded iteratively backwards deleting from the models nonsignificant terms until all effects and/or interactions retained significance $(P<0.05)$. The nonsignificance of the removed terms was further confirmed by adding them one by one to the final model. Sample sizes differ among analyses because not all data were known for all individuals.

\section{Annual survival and transition probabilities}

Because the expression of the forehead patch varies at the within-individual level, we used multistate CMR models (Nichols \& Kendall, 1995; Lebreton \& Pradel, 2002) to analyse whether female annual survival is related to the expression or not of the forehead patch (two states) and to estimate transition rates within and between states (i.e. the probability of changing from ornamented to nonornamented and vice versa) while correcting for recapture rates. The general model was the time- and state-dependent Arnason-Schwarz model (Brownie et al., 1993) besides an age effect with two age classes (first-breeders and older individuals). As both newborn and adult birds were marked in our population, these two groups were distinguished in the models by assuming that survival, recapture and transition parameters were equal for birds marked as adult and for the adult stages of birds marked as fledglings. This general model incorporating time-, age- and statedependent variations in survival $(\phi)$, reencounter $(p)$ and transition probabilities $(\psi)$ resulted in a large number of inestimable parameters, so we began with a constrained model in which transition rates varied between states and age classes but were constant over time. This model was denoted $\phi_{\left(\mathrm{t}^{*} \mathrm{a} 2^{*} \mathrm{~m}\right)} p_{\left(\mathrm{t}^{*} \mathrm{a} 2^{*} \mathrm{~m}\right)} \mathrm{y}_{\left(\mathrm{a} 2^{*} \mathrm{~m}\right)}$, subscripts $\mathrm{t}, \mathrm{a} 2$ and $\mathrm{m}$ indicating time-, age- and ornament-specific parameters, respectively. In addition, we parameterized single-state Cormack-Jolly-Seber (CJS) models to investigate whether expressing the ornament at an early age ( 1 or 2 years old) affected apparent survival 
and reencounter probabilities. Our general model was $\phi_{\left(\mathrm{t}^{*} \mathrm{~g}\right)} p_{\left(\mathrm{t}^{*} \mathrm{~g}\right)}$, where $\mathrm{t}$ indicates time-constrained parameters and $g$ two groups of individuals (expressing or not the ornament at an early age).

We first assessed goodness-of-fit (GOF) of the JollyMove (JMV) and CJS models (for multistate and singlestate models, respectively) using software U-CARE (Pradel et al., 2003; Choquet et al., 2009). Then, all models were fitted to the data using program MARK (v. 5.1; White \& Burnham, 1999). As no recapture effort was made in 2003, the corresponding reencounter parameter for this occasion was set to 0 . Model selection was based on the Akaike information criterion corrected (AICc) for small sample sizes, models within 2 AICc points being considered equal (Burnham \& Anderson, 1998). We also calculated the relative plausibility of each model with normalized Akaike weights and used multimodel inference (model averaging) when more than one model had substantial support (Burnham \& Anderson, 1998).

\section{Lifetime analyses}

Generalized mixed models were also employed to ascertain whether patch expression correlated with lifetime breeding performance, that is, number of eggs, fledglings and recruits produced throughout lifetime. Model structures and selection were similar to those described for annual parameters (Poisson error for lifetime number of eggs and binomial models with previous stage as a denominator for numbers of fledglings and recruits). Cohort identity was fitted as a random term and age at first breeding, longevity and patch expression as fixed terms. As stated above, two sets of models were carried out by considering (i) whether the female expressed the ornament at least once throughout her life and (ii) whether she expressed the ornament or not at 1-2 years of age.

\section{Results}

A forehead patch was recorded at least once in 172 of 466 females followed throughout their lifetimes $(36.9 \%)$. Thus, contrary to males where the forehead patch is expressed by all individuals to a variable degree, only a minority of females express the trait. Summary statistics of components of LRS in ornamented and nonornamented females are given in Table 1 .

\section{Age dependency of female ornamentation}

Female expression of the ornament was related to age as only $6 \%$ of yearling females compared to $40 \%$, on average, of the older females expressed the trait $\left(n=846\right.$ records of 466 individuals; $\chi_{6}^{2}=148.66$, $P<0.0001$; Fig. 1a). The age when the ornament was first recorded was very variable, ranging from 1 to
8 years $\quad($ median $=2, \quad$ mean $\pm S D=2.7 \pm 1.2$ years $)$, with most females $(75 \%)$ starting to display it in their second or third year (Fig. lb).

The likelihood of expressing the ornament increased with age (Fig. 1c) and was due to within-individual variation, not to the selective appearance or disappearance of ornament-related expression of phenotypes in the
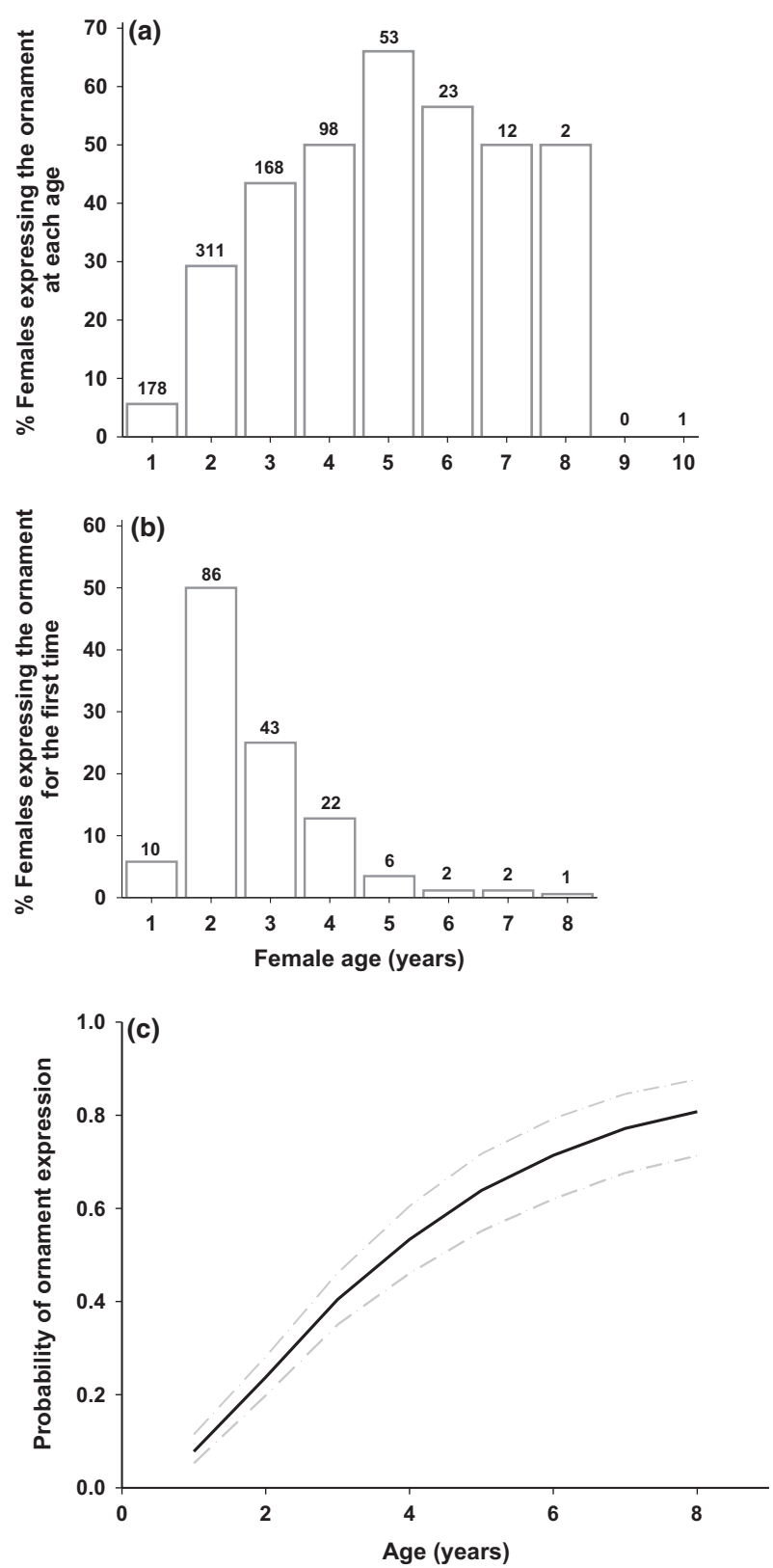

Fig. 1 Percentages of females expressing the ornament in relation to their age (a) and their age at first expression (b); the probability of expressing the ornament (mean estimate $\pm 95 \% \mathrm{CI}$ ) as derived from model parameters is shown in (c). Numbers above bars are sample sizes. 
population (binomial mixed model; estimate LogAge (SE) 0.0459 (0.0066), $F_{1,379}=48.22, P<0.0001$; estimate (SE) age at first measurement -0.01342 (0.1502), $F_{1,379}=0.01, P=0.9577$; estimate $(\mathrm{SE})$ age at last measurement $\left.-0.0509(0.0916), F_{1,379}=0.39, P=0.5337\right)$.

\section{Annual reproductive success and female ornament expression}

Clutch size

Females expressing the forehead patch in a given year laid significantly larger clutches than those not expressing it. As shown by the slope of the final model, ornamented females lay, on average, 0.129 more eggs per clutch than nonornamented individuals (Table 2, Fig. 2). Similarly to ornament expression, the increase in clutch size with increasing age was due to withinindividual changes, not to selective effects in the population (Table 2).

\section{Fledging success}

The yearly numbers of fledged young, after taking clutch size into account, were affected by an interaction between age and female ornament expression status (Table 3, Fig. 2). Nonornamented females tended to rear larger broods with increasing age, following the pattern due to corresponding increases in clutch size, whereas ornamented females started strongly but their fledging production tended to decline as they aged (Fig. 2). As a result, the older ornamented females reared, on average, as few nestlings as nonornamented yearling females even though they laid larger clutches.

\section{Recruitment success}

After controlling for female age and number of young fledged, there was no effect of expressing the forehead patch in a given breeding season on the number that recruited as breeders in later years. However, there were effects of both the age at which the individual was recorded in the population for the first and the last

Table 2 GLMM showing the effect of female age and forehead patch expression on clutch size in female pied flycatchers. LogAge indicates within-individual age effects on a logarithmic scale. Models were fitted with Poisson distribution of errors and log link function.

\begin{tabular}{|c|c|c|c|c|}
\hline & Estimate & SE & $F$ & $P$ \\
\hline Intercept & 6.0906 & 0.1245 & & \\
\hline FP expression & & & 5.18 & 0.0234 \\
\hline Yes & 0 & & & \\
\hline No & -0.1294 & 0.0568 & & \\
\hline LogAge & 0.6124 & 0.1203 & 25.92 & $<0.0001$ \\
\hline Laying date & -0.03368 & 0.0039 & 76.59 & $<0.0001$ \\
\hline d.f. & 1360 & & & \\
\hline
\end{tabular}

GLMM, generalized mixed models.
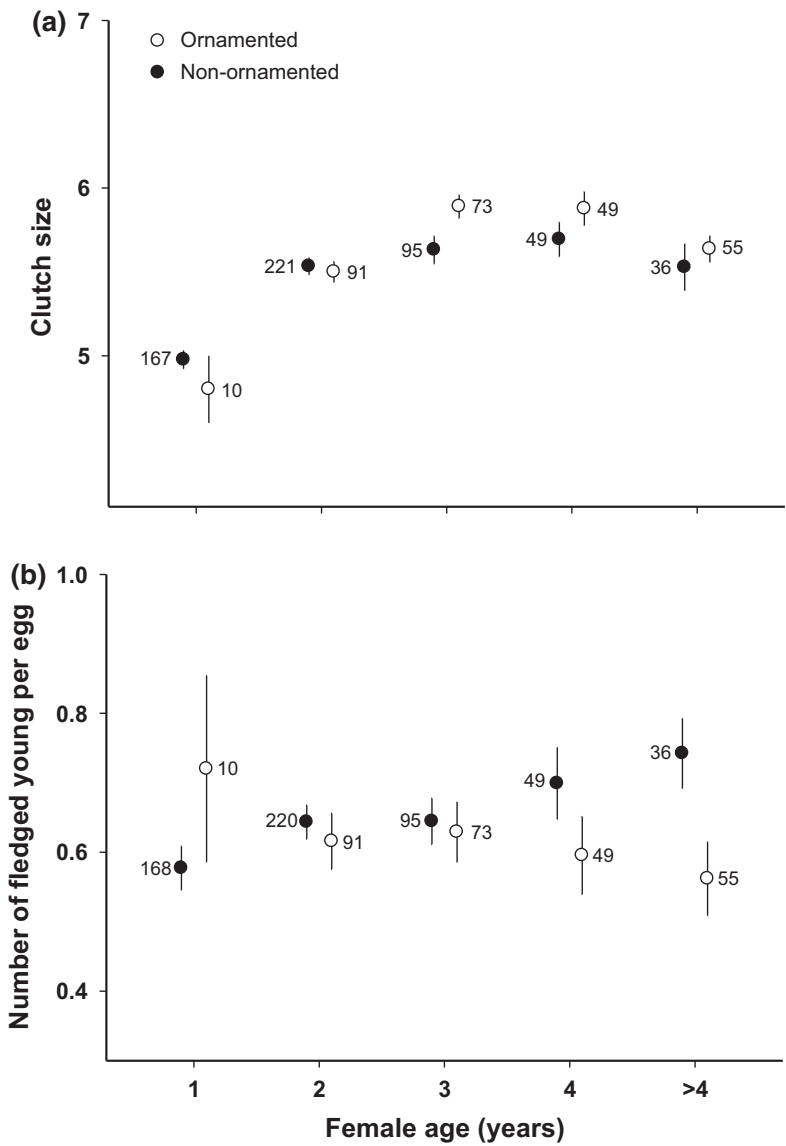

Fig. 2 Variation (mean \pm SE) in clutch size (a) and fledged young (b) in relation to female age and the concurrent expression (or lack thereof) of the forehead patch by female pied flycatchers; open and filled dots denote ornamented and nonornamented females, respectively; numbers besides bars are numbers of females.

Table 3 GLMM showing the effect of female age and forehead patch expression on numbers of young fledged by female pied flycatchers after controlling for clutch size (binomial error, number of eggs as a binomial denominator and logit link function). LogAge indicates within-individual age effects on a logarithmic scale. See Table S1 for equivalent analyses of absolute numbers of fledglings.

\begin{tabular}{lclll}
\hline & Estimate & SE & $F$ & $P$ \\
\hline $\begin{array}{l}\text { Intercept } \\
\text { FP expression } \\
\quad \text { Yes }\end{array}$ & 2.6630 & 0.4432 & & \\
$\quad$ No & 0 & & 2.75 & 0.0980 \\
LogAge & -0.4855 & 0.2926 & & \\
Fp expression $\times$ LogAge & -1.2804 & 0.5501 & 1.59 & 0.2086 \\
$\quad$ Yes & 0 & & 8.35 & 0.0041 \\
$\quad$ No & 1.6702 & 0.5781 & & \\
Laying date & -0.05470 & 0.009793 & 31.20 & $<0.0001$ \\
d.f. & 1341 & & & \\
\hline
\end{tabular}

GLMM, generalized mixed models. 
time across lifetime, so that the number of recruits was larger for females breeding at early ages and for those captured for the last time at older ages (Table 4).

\section{Annual survival and transition probabilities}

The GOF tests indicated that both JMV and CJS models fitted the data well (JMV: $\chi_{87}^{2}=50.93, P=0.99$; CJS: $\left.\chi_{44}^{2}=10.29, P=1.00\right)$. Multistate analyses were little informative as to differences in yearly survival rates in relation to expression of the forehead patch in females, as revealed by the four highest-ranked candidate models (those with $\triangle \mathrm{AICc}<2$; Table 5 ). Model averaging of these top-ranked models pointed to a very small difference $(<2 \%)$ in female survival between females expressing or not the forehead patch. Models including different transition probabilities for each state had, however, overwhelming support (Table 6; $w_{i}=0.999$ ). The between-year probability of remaining ornamented was $0.86 \pm 0.03$ (SE), indicating that once expressed most females displayed the ornament in subsequent breeding seasons. Nonornamented females had a smaller probability $(0.74 \pm 0.03)$ of remaining within the nonornamented state in the subsequent year. Consequently, the probability of changing from nonornamented to ornamented state was almost twice as large as the opposite $(0.26 \pm 0.03$ vs. $0.14 \pm 0.03)$.

Cormack-Jolly-Seber candidate models analysing survival and recapture probabilities as functions of ornament expression at early ages (1-2 year old) are shown in Table 6. The top-ranked model was 2.9 times better supported than the next best model, suggesting that females expressing the forehead patch at an early age had a probability of survival about $10 \%$ greater than those that did not $(0.60 \pm 0.04$ vs. $0.49 \pm 0.02$; Fig. 3). This translates to a higher mean life expectancy (Seber, 1982) of 1.93 (95\% CI: 1.55-2.43) years for individuals expressing the ornament at early ages, as opposed to $1.40(1.25-1.59)$ years for those expressing the forehead patch at older ages or not expressing it at all.

Table 4 GLMM showing the effect of female age and forehead patch expression on numbers of recruits of female pied flycatchers after correcting for the number of fledged young (binomial error, fledglings as a binomial denominator and logit link function). Age at first and last measurements indicates the selective appearance and disappearance of phenotypes, respectively. See Table S1 for equivalent analyses of absolute numbers of recruits.

\begin{tabular}{lrlll}
\hline & Estimate & SE & $F$ & $P$ \\
\hline Intercept & -1.3357 & 0.3625 & & \\
Age at first measurement & -0.2251 & 0.0955 & 5.56 & 0.0193 \\
Age at last measurement & 0.1304 & 0.0470 & 7.70 & 0.0061 \\
Laying date & -0.0346 & 0.0117 & 8.75 & 0.0035 \\
d.f. & 1198 & & & \\
\hline
\end{tabular}

GLMM, generalized mixed models.
Table 5 Candidate multistate capture-recapture models. Shown are AICc, difference in AICc with the highest-ranked model $(\triangle \mathrm{AICC})$, model weight, number of identifiable parameters $(K)$ and deviance for survival $(\phi)$, reencounter $(p)$ and transition $(\psi)$ probabilities of female pied flycatchers.

\begin{tabular}{|c|c|c|c|c|c|}
\hline Model & $\mathrm{AlCc}$ & $\Delta \mathrm{AlCc}$ & AlCc Weight & K & Deviance \\
\hline$\phi_{(\mathrm{a} 2)} P_{\left(\mathrm{t}^{\star} \mathrm{m}\right)} \psi_{(\mathrm{m})}$ & 1767.714 & 0 & 0.3161 & 22 & 517.30 \\
\hline$\phi_{(.)} p_{\left(t^{*} m\right)} \psi_{(m)}$ & 1768.392 & 0.6779 & 0.2252 & 21 & 520.08 \\
\hline$\phi_{(\mathrm{a} 2+\mathrm{m})} p_{\left(\mathrm{t}^{\star} \mathrm{m}\right)} \psi_{(\mathrm{m})}$ & 1769.296 & 1.5821 & 0.1433 & 23 & 516.76 \\
\hline $\begin{array}{c}\left.\left.\phi_{(\mathrm{a} 2[1} \mathrm{yr} \mathrm{r}^{\star} \mathrm{m}, \mathrm{ad}\right]\right) \\
p_{\left(\mathrm{t}^{\star} \mathrm{m}\right)} \psi_{(\mathrm{m})}\end{array}$ & 1769.689 & 1.975 & 0.1177 & 23 & 517.16 \\
\hline$\phi_{(\mathrm{m})} p_{\left(\mathrm{t}^{\star} \mathrm{m}\right)} \psi_{(\mathrm{m})}$ & 1770.456 & 2.7426 & 0.0802 & 22 & 520.04 \\
\hline$\phi_{(\mathrm{a} 2)} p_{\left(\mathrm{t}^{*} \mathrm{~m}\right)} \psi_{\left(\mathrm{a} 2^{*} \mathrm{~m}\right)}$ & 1770.878 & 3.1643 & 0.0649 & 24 & 516.23 \\
\hline$\phi_{\left(\mathrm{a} 2^{*} \mathrm{~m}\right)} P_{\left(\mathrm{t}^{*} \mathrm{~m}\right)} \psi_{(\mathrm{m})}$ & 1771.371 & 3.6575 & 0.0507 & 24 & 516.72 \\
\hline$\phi_{(\mathrm{a} 2)} P_{\left(\mathrm{t}^{*} \mathrm{~m}\right)} \psi_{(.)}$ & 1779.589 & 11.8752 & 0.0008 & 24 & 524.94 \\
\hline$\phi_{(\mathrm{t})} p_{\left(\mathrm{t}^{\star} \mathrm{m}\right)} \psi_{(\mathrm{m})}$ & 1780.664 & 12.9501 & 0.0004 & 36 & 500.17 \\
\hline$\phi_{(\mathrm{t}+\mathrm{m})} p_{\left(\mathrm{t}^{*} \mathrm{~m}\right)} \psi_{(\mathrm{m})}$ & 1782.417 & 14.7036 & 0.0002 & 37 & 499.74 \\
\hline$\phi_{\left(\mathrm{t}{ }^{*} \mathrm{~m}\right)} P_{\left(\mathrm{t}^{\star} \mathrm{m}\right)} \psi_{(\mathrm{m})}$ & 1792.891 & 25.1775 & 0 & 46 & 490.27 \\
\hline$\phi_{(\mathrm{a} 2)} p_{(\mathrm{t})} \psi_{(\mathrm{m})}$ & 1795.672 & 27.9582 & 0 & 18 & 553.66 \\
\hline$\phi_{(\mathrm{a} 2)} p_{(\mathrm{t}+\mathrm{m})} \psi_{(\mathrm{m})}$ & 1796.954 & 29.2401 & 0 & 19 & 552.85 \\
\hline$\phi_{\left(\mathrm{t}^{*} \mathrm{~m}\right)} p_{\left(\mathrm{t}^{\star} \mathrm{m}\right)} \psi_{(.)}$ & 1799.433 & 31.7194 & 0 & 45 & 499.05 \\
\hline$\left.\phi_{(\mathrm{t}}{ }^{*} \mathrm{~m}\right) P_{(\mathrm{t})} \psi_{(\mathrm{m})}$ & 1816.579 & 48.8648 & 0 & 42 & 522.87 \\
\hline
\end{tabular}

AICc, akaike information criterion corrected.

Subscripts denote age (a2), time $(t)$ and ornament $(\mathrm{m})$ effects. Symbol ' $*$ ' denotes interaction, and symbol ' + ' additive effects. a2 [1 year*m, ad] indicates age dependency with an ornament effect in yearlings, but not in adults. Only the 15 top-ranked models are shown.

\section{LRS and female ornament expression}

Similarly to the analyses of yearly reproductive success, analyses of fitness components across lifetime showed that ornamented females were more fecund, that is, they laid more eggs during their reproductive careers, than nonornamented ones even after taking longevity into account (Table 7a). Expressing the ornament at early ages did not influence lifetime number of eggs (Table 7a), but that effect became apparent when longevity was removed from the model (estimate for nonornamented females at early ages $=-0.2227 \pm$ $0.04335, F_{1,276}=8.87, P=0.0032$ ), indicating that the differences were mainly due to differential lifespans between both groups of individuals, in accordance with analyses of survival probabilities (see above). Lifetime fledging success (number of fledglings/number of eggs) was slightly associated with ornament expression (Table 7b). The relationship between expressing the ornament at early ages and lifetime fledging production was marginally nonsignificant when longevity was maintained in the model (Table $7 \mathrm{~b}$ ), but again the effect was stronger when this variable was removed (estimate for nonornamented females at early ages $=-0.2345 \pm$ $\left.0.09282, F_{1,284}=6.38, P=0.0121\right)$. In contrast, lifetime recruit production was unrelated to female trait expression both throughout lifetime and at early ages (Table 7c), and this result persisted when longevity was removed from analyses. 
Table 6 Candidate CJS capture-recapture models. Shown are AICc, difference in AICc with the highest-ranked model ( $\triangle \mathrm{AICc})$, model weight, number of identifiable parameters $(K)$ and deviance for survival $(\phi)$ and reencounter $(p)$ probabilities of female pied flycatchers.

\begin{tabular}{|c|c|c|c|c|c|}
\hline Model & $\mathrm{AlCc}$ & $\Delta \mathrm{AlCc}$ & AlCc Weight & K & Deviance \\
\hline$\phi_{(\mathrm{g})} p_{\left(\mathrm{g}^{*} \mathrm{t}\right)}$ & 1172.233 & 0 & 0.70554 & 22 & 198.2186 \\
\hline$\phi_{(.)} p_{\left(g^{*} t\right)}$ & 1174.391 & 2.1574 & 0.23991 & 20 & 204.623 \\
\hline$\phi_{(\mathrm{g})} p_{(\mathrm{t})}$ & 1178.008 & 5.7745 & 0.03932 & 17 & 214.5657 \\
\hline$\phi_{(.)} p_{(t)}$ & 1180.041 & 7.8075 & 0.01423 & 15 & 220.7862 \\
\hline$\phi_{(\mathrm{t})} P_{\left(\mathrm{g}^{*} \mathrm{t}\right)}$ & 1185.687 & 13.4537 & 0.00085 & 33 & 187.8769 \\
\hline$\phi_{(\mathrm{t})} p_{(\mathrm{t})}$ & 1190.431 & 18.1977 & 0.00008 & 28 & 203.5297 \\
\hline$\phi_{\left(g^{*} t\right)} p_{(t)}$ & 1191.063 & 18.8302 & 0.00006 & 39 & 179.9539 \\
\hline$\phi_{\left(g^{*} t\right)} p_{\left(g^{*} t\right)}$ & 1193.012 & 20.7793 & 0.00002 & 44 & 170.6418 \\
\hline$\phi_{(\mathrm{t})} p_{(.)}$ & 1223.601 & 51.3681 & 0 & 17 & 260.1593 \\
\hline$\phi_{(\mathrm{t})} p_{(\mathrm{g})}$ & 1225.672 & 53.4384 & 0 & 18 & 260.127 \\
\hline$\phi_{\left(g^{\star} \mathrm{t}\right)} p_{(.)}$ & 1226.379 & 54.1455 & 0 & 29 & 237.3082 \\
\hline$\phi_{\left(\mathrm{g}^{*} \mathrm{t}\right)} p_{(\mathrm{g})}$ & 1228.324 & 56.091 & 0 & 30 & 237.0782 \\
\hline$\phi_{(\mathrm{g})} p_{(.)}$ & 1255.008 & 82.7752 & 0 & 3 & 320.3941 \\
\hline$\phi_{(\mathrm{g})} p_{(\mathrm{g})}$ & 1256.689 & 84.4556 & 0 & 4 & 320.0523 \\
\hline$\phi_{(.)} p_{(.)}$ & 1258.68 & 86.4469 & 0 & 2 & 326.0824 \\
\hline
\end{tabular}

AICc, akaike information criterion corrected; CJS, Cormack-JollySeber.

Subscripts denote time $(t)$ and ornament expression early in life $(\mathrm{g})$ effects. Symbol ' $*$ ' denotes interaction, and symbol ' + ' additive effects. Only the 15 top-ranked models are shown.

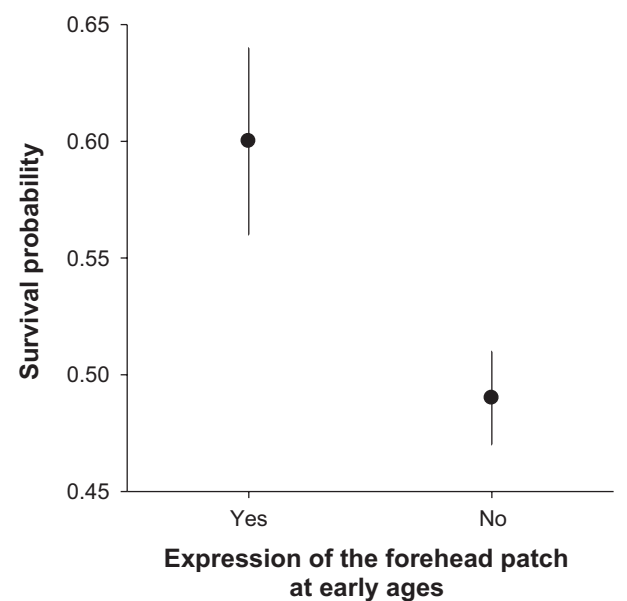

Fig. 3 Differences in survival probability ( \pm SE) between females expressing or not the ornament at early ages (1-2 years old).

\section{Discussion}

We have presented long-term evidence on the covariation among the expression of a 'male' secondary sex trait displayed by a fraction of females with their yearly and lifetime fitness in the pied flycatcher, a model species in sexual selection studies. This study thus adds to the scant, long-term evidence on the ecological and evolutionary significance of ornament displaying by
Table 7 Results of GLMM analyses of components of lifetime reproductive success (total number of eggs laid, young fledged and recruits) of female pied flycatchers in relation to the expression (yes/no) of the forehead patch (FP) both throughout lifetime and at early ages (1-2 years). The lifetime number of eggs laid was modelled with a Poisson distribution of errors and a log link function. Lifetime fledglings and recruits were modelled with binomial errors and logit link functions using the number of eggs and the number of fledglings as binomial denominator, respectively. See Table S2 for equivalent analyses of absolute numbers of fledglings and recruits.

\begin{tabular}{|c|c|c|c|c|}
\hline & Estimate & SE & $F$ & $P$ \\
\hline \multicolumn{5}{|c|}{ (a) Total number of eggs laid } \\
\hline \multicolumn{5}{|c|}{ FP expressed throughout lifetime } \\
\hline Intercept & 1.3896 & 0.07664 & & \\
\hline FP expression & & & 7.94 & 0.0051 \\
\hline Yes & 0 & & & \\
\hline No & -0.1007 & 0.03574 & & \\
\hline Age of first breeding & -0.2986 & 0.02802 & 113.56 & $<0.0001$ \\
\hline Longevity & 0.3857 & 0.01398 & 761.53 & $<0.0001$ \\
\hline d.f. & 1322 & & & \\
\hline \multicolumn{5}{|c|}{ FP expressed at early ages } \\
\hline Intercept & 1.2756 & 0.05426 & & \\
\hline Age of first breeding & -0.3150 & 0.02499 & 158.96 & $<0.0001$ \\
\hline Longevity & 0.4055 & 0.01109 & 1337.92 & $<0.0001$ \\
\hline d.f. & 1451 & & & \\
\hline \multicolumn{5}{|c|}{ (b) Total number of fledged young } \\
\hline \multicolumn{5}{|c|}{ FP expressed throughout lifetime } \\
\hline Intercept & 0.7780 & 0.08590 & & \\
\hline FP expression & & & 4.14 & 0.0428 \\
\hline Yes & 0 & & & \\
\hline No & -0.1449 & 0.07124 & & \\
\hline d.f. & 1331 & & & \\
\hline \multicolumn{5}{|c|}{ FP expressed at early ages } \\
\hline Intercept & 0.5714 & 0.1951 & & \\
\hline FP expression & & & 3.70 & 0.0553 \\
\hline Yes & 0 & & & \\
\hline No & -0.1816 & 0.09435 & & \\
\hline Longevity & 0.1032 & 0.03285 & 9.87 & 0.0019 \\
\hline d.f. & 1283 & & & \\
\hline \multicolumn{5}{|c|}{ c) Total number of recruits } \\
\hline \multicolumn{5}{|c|}{ FP expressed throughout lifetime } \\
\hline Intercept & -2.4431 & 0.1826 & & \\
\hline Longevity & 0.1221 & 0.04031 & 9.17 & 0.0026 \\
\hline d.f. & 1411 & & & \\
\hline \multicolumn{5}{|c|}{ FP expressed at early age } \\
\hline Intercept & -2.4431 & 0.1826 & & \\
\hline Longevity & 0.1221 & 0.04031 & 9.17 & 0.0026 \\
\hline d.f. & 1411 & & & \\
\hline
\end{tabular}

GLMM, generalized mixed models.

both sexes in wild vertebrates (Roulin et al., 2010). Ornamented female pied flycatchers had increased (yearly and lifetime) fecundity and fledging success, suggesting that, regardless of the association between trait expression and age, expressing the trait on its own may signal an added age-independent (Hegyi et al., 2006) component to female quality. Interestingly, lon- 
gitudinal analyses showed that ornamented females had a lower fledging success late in life than nonornamented females at advanced ages. Taken together, these results point to different 'strategies' of female ornament expression leading to similar payoffs in the long-term, with no differences in final fitness (as measured by recruitment rates) but on the life-history trajectories followed to attain it. On the one hand, females expressing the ornament seem to invest more in reproduction at early ages than nonexpressing females. Although ornamented females did not suffer apparent costs in survival (with the group of females expressing the ornament at early ages constituting in fact the most longeve group), they appear to pay those costs in terms of decreased fledging success at the older ages, in what seems a symptom of accelerated senescence that, unlike in most comprehensive studies performed to date, is paid in lowered fledging output, not in decreased clutch size (Gustafsson \& Pärt, 1990) or in diminished survival prospects at older ages (Orrell \& Belda, 2002). Females not expressing the forehead patch, on the other hand, seem to follow a slower pace of life, with a trajectory of gradual improvement in reproductive performance with increasing age without incurring in late-life declines in breeding output.

\section{The female ornament as a quality indicator}

When ornaments signal female quality, ornament expression should be related to different components of fitness. In birds, including the pied flycatcher (Morales et al., 2007), there was previous support for positive associations between female ornaments and annual reproductive success (Velando et al., 2001; Massaro et al., 2003; Siefferman \& Hill, 2005; Dey et al., 2012), and other studies are also consistent with a role of female ornaments as likely indicators of quality (Roulin et al., 2000; Griggio et al., 2005; Kraaijeveld et al., 2007; Vergara et al., 2009; Martínez-Padilla et al., 2011; but see Tella et al., 1997). In contrast, studies examining the association between female ornamentation and LRS, an essential step to assess the adaptiveness of female ornamentation, are much scarcer (Roulin et al., 2010; Dey et al., 2012), and even the predicted relationship with an important fitness components (survival prospects; Andersson, 1994) was far from evident in the review of Amundsen and Pärn (2006). Combined with patterns of expression with age (Fig. 1), the increased lifetime fecundity (in terms of eggs laid and fledglings reared) of females displaying the forehead patch, the enhanced survival of those expressing it at early ages and the diminished fledging production of females that remain ornamented late in life suggest that displaying the forehead patch may be a costly indicator of quality in female pied flycatchers, even if the number of young they recruited did not differ significantly from that of nonornamented females. However, the caveat should be made that recruitment rates are sub- jected to large stochastic variation, implying a progressively vanishing influence of maternal quality over long timescales (e.g. after independence from parental care and later in adult life; Price, 1998) what would explain the lack of association between ornamentation and recruitment rates. Under this viewpoint, therefore, our results would suggest that ornamented females are indeed of higher quality than nonornamented ones.

Models of evolution of female ornamentation through resource (food, territories, nests, mates) competition state that some ornaments may function in females as agonistic signals in conflict resolution or either signal dominance, as it is common in males (Andersson, 1994; Owens et al., 1994; Swaddle \& Witter, 1995; LeBas, 2006; Murphy et al., 2009; Griggio et al., 2010; Midamegbe et al., 2011; Rosvall, 2011; Tobias et al., 2012). For instance, in the related collared flycatcher (Pärt \& Qvärnstrom, 1997), the wing patch (another achromatic sex dimorphic signal) functions as a male sexual signal (Sheldon \& Ellegren, 1999; Hegyi et al., 2008; de Heij et al., 2011) and is also involved in female agonistic behaviour against territorial intruders. Pryke (2007) has speculated that behavioural differences in dominance, maybe mediated by androgen levels, could result from linkage and/or pleiotropic interactions between genes controlling levels of dominance, aggression and expression of ornaments. Some important components of this scenario, as additive genetic variance and between-sex genetic correlation in ornament size, as well as significant female offspringfemale parent resemblance in ornament expression, are present in at least some pied flycatcher populations (Potti \& Canal, 2011). Thus, this might be an example that genetic correlations may act as a 'preadaptation' for functional female decoration (Amundsen, 2000b).

As its determination has a heritable basis of both size (both sexes; $h^{2}=0.5$ ) and expression (females only; $h^{2}=0.3$; Potti \& Canal, 2011), it may appear intriguing why the ornament is not displayed by all females, suggesting that its mere expression in this sex may be environmentally induced, epigenetically modified (Badyaev, 2004) and ultimately maintained through a balance between evolutionary benefits and costs. Under the theory of honest signalling, only high-quality individuals can afford the more costly expressions of ornaments (Zahavi, 1975; Grafen, 1990; Dale, 2006). Likely proximate (physiological or behavioural) costs to trait expression could be, for instance, increased predation risk due to enhanced detectability by predators (Götmark et al., 1997), escalated costs of immunological defence against parasites in ornamented females (Folstad \& Karter, 1992) or increased rates of aggression by other individuals (Berglund et al., 2008; Cain et al., 2011). Further detailed, preferably experimental studies (Blount et al., 2002; McGraw et al., 2005; Doutrelant et al., 2008; Gasparini et al., 2009; Kekäläinen et al., 2010; Martínez-Padilla et al., 2011) as the recent one of 
Moreno et al. (2012) are needed. By experimentally manipulating forehead patches of female pied flycatchers in a nearby Iberian population, that study has shown that female Iberian pied flycatchers pay costs, in terms of oxidative damage, when expressing the ornament. These authors suggest that the female forehead patch may function as a badge of status under socially mediated control, with females lacking the ornament incurring in less physiological costs while breeding but maybe suffering competitive exclusion from breeding resources (Moreno et al., 2012). From results presented herein, we suggest that fitness advantages are compensating the costs of ornament expression in at least a fraction of females, thus ultimately being involved in the maintenance of the within-sex dimorphism of lifetime ornament expression in female pied flycatchers.

\section{Trait coevolution between the sexes}

The evidence here reported suggests that ornament expression in female pied flycatchers is a target of selection and also that sexually antagonistic coevolution is not strong at the stage of the dynamic (Lande, 1980; Bonduriansky \& Chenoweth, 2009) coevolutionary race between the sexes in which the population seems to be presently immersed (Potti \& Canal, 2011). For genetic sexual conflict to occur, there should be some degree of sexually antagonistic selection, but signs of directional selection in both sexes (on trait expression in females, on trait size in males) have been observed instead. Why forehead patch expression is positively associated with some fitness components could then be due to two alternative processes. On the one hand, the patch may represent a direct target of selection. On the other hand, ornament expression could have no 'true' functional significance in females, but still remain correlated with fitness by virtue of its association with heritable quality in males and due to a genetic correlation between the sexes (which is near unity for ornament size; Potti \& Canal, 2011) that should be reinforced by the pattern of assortative mating regarding ornament size (Lande, 1980; Kraaijeveld et al., 2007; Kekäläinen et al., 2010). However, in the first case, the same trait would be under positive selection in both sexes, whereas in the latter case females carrying 'good genes' would be those expressing the male-like ornament (again suggesting that sexual genetic conflict might be weak or absent). Our analyses cannot fully discriminate between both explanations as we still do not know whether females expressing the ornament are those with 'good genes', inheriting male quality. To quantify the relative importance of each type of explanation, a full assessment of selection on ornament in males will be needed as well (Kraaijeveld et al., 2007; Bonduriansky \& Chenoweth, 2009; Roulin et al., 2010, 2011). However, a major drawback to that approach is that a joint selection assessment in males and females can only be performed on ornament size, as ornament expression is universal in males (at least in Iberian populations), making uncertain predictions merely involving its rather limited expression in females (cf. Roulin et al., 2010).

In conclusion, we have presented evidence on variation in a secondary sex trait that is differentially expressed in both sexes being related to lifetime-based benefits and costs of its expression in females. Future work on ornaments shared by males and females should ideally combine molecular (Nadeau et al., 2007; Wright et al., 2007; Williams \& Carroll, 2009; Khila et al., 2012; Lehtonen et al., 2012), observational and manipulative studies in both sexes to reveal the intricacies of proximate, including genetic, epigenetic and environmental, influences underlying their phenotypic expression.

\section{Acknowledgments}

We thank Carlos Camacho, Óscar Frías and Inés Valencia for their excellent assistance with field work. We are most grateful to Roger Jovani and László Zsolt Garamszegi (LZG) for very valuable discussions. JP and DC warmly thank LZG and Juan J. Negro for important financial support in dire times. Constructive comments by reviewers are gratefully acknowledged. Consejería de Medio Ambiente, Comunidad de Madrid and Delegación de Medio Ambiente, Junta de Castilla-La Mancha gave us working permissions. DC was supported by a grant from the Ministerio de Educación y Ciencia (I3P-BDP2005) and also thanks Paola Laiolo for financial help. JP's long-term work has been funded by the Spanish Government, most recently by projects CGL2009-10652, CGL2011-29694 and CGL2012-35232.

\section{Conflict of interest}

None declared.

\section{References}

Amundsen, T. 2000a. Female ornaments: genetically correlated or sexually selected? In: Animal Signals (Y. Espmark, T. Amundsen \& G. Rosenqvist, eds), pp. 133-154. Tapir Academic Press, Trondheim.

Amundsen, T. 2000b. Why are female birds ornamented? Trends Ecol. Evol. 15: 149-155.

Amundsen, T. \& Forsgren, E. 2001. Male mate choice selects for female coloration in a fish. Proc. Natl Acad. Sci. USA 98 13155-13160.

Amundsen, T. \& Pärn, H. 2006. Female coloration in birds: a review of functional and non-functional hypotheses. In: Bird Coloration. Vol. 2 (G.E. Hill \& K.J. McGraw, eds), pp. 280345. Harvard University Press, Cambridge, MA.

Andersson, M. 1994. Sexual Selection. Princeton University Press, Princeton, NJ.

Andrés, J.A. \& Morrow, E.H. 2003. The origin of interlocus sexual conflict: is sex-linkage important? J. Evol. Biol. 16: 219-223. 
Badyaev, A.V. 2004. Integration and modularity in the evolution of sexual ornaments. An overlooked perspective. In: Phenotypic Integration. Studying the Ecology and Evolution of Complex Phenotypes (M. Pigliucci \& K. Preston, eds), pp. 50-79. Oxford Univ. Press, Oxford.

Berglund, A., Rosenqvist, G. \& Bernet, P. 1997. Ornamentation predicts reproductive success in female pipefish. Behav. Ecol. Sociobiol. 40: 145-150.

Berglund, A., Bisazza, A. \& Pilastro, A. 2008. Armaments and ornaments: an evolutionary explanation of traits of dual utility. Biol. J. Linn. Soc. 58: 385-399.

Blount, J.D., Surai, P.F., Nager, R.G., Houston, D.C., Møller, A.P., Trewby, M.L. et al. 2002. Carotenoids and egg quality in the lesser black-backed gull Larus fuscus: a supplemental feeding study of maternal effects. Proc. R. Soc. Lond. B 269: 29-36.

Bolker, B.M., Brooks, M.E., Clark, C.J., Geange, S.W., Poulsen, J.R., Stevens, M.H.H. et al. 2008. Generalized linear mixed models: a practical guide for ecology and evolution. Trends Ecol. Evol. 24: 127-135.

Bonduriansky, R. 2011. Sexual selection and conflict as engines of ecological diversification. Am. Nat. 178: 729-745.

Bonduriansky, R. \& Chenoweth, S.F. 2009. Intralocus sexual conflict. Trends Ecol. Evol. 24: 280-288.

Brommer, J.E., Ahola, K. \& Karstinen, T. 2005. The colour of fitness: plumage colouration and lifetime reproductive success in the tawny owl. Proc. R. Soc. Lond. B 272: 935-940.

Brownie, C., Hines, J., Nichols, J., Pollock, K. \& Hestbeck, J. 1993. Capture-recapture studies for multiple strata including non-Markovian transitions. Biometrics 49: 1173-1187.

Burley, N. 1983. The meaning of assortative mating. Ethol. Sociobiol. 4: 191-203.

Burnham, K.P. \& Anderson, D.R. 1998. Model Selection and Inference. Springer, New York, NY.

Cain, K.E., Rich, M.S., Ainsworth, K. \& Ketterson, E.D. 2011. Two sides of the same coin? consistency in aggression to conspecifics and predators in a female songbird. Ethology 117: 786-795.

Canal, D., Potti, J. \& Dávila, J.A. 2011. Male phenotype predicts extra pair paternity in pied flycatchers. Behaviour 148 691-712.

Canal, D., Jovani, R. \& Potti, J. 2012. Multiple mating opportunities boost protandry in a pied flycatcher population. Behav. Ecol. Sociobiol. 66: 67-76.

Choquet, R., Lebreton, J.-D., Gimenez, O., Reboulet, A.M. $\delta$ Pradel, R. 2009. U-CARE: utilities for performing goodness of fit tests and manipulating CApture-REcapture data. Ecography 32: 1071-1074.

Clutton-Brock, T.H. 1988. Reproductive Success. University of Chicago Press, Chicago, IL.

Clutton-Brock, T.H. 2007. Sexual selection in males and females. Science 318: 1882-1885.

Cotton, S., Fowler, K. \& Pomiankowski, A. 2004. Do sexual ornaments demonstrate heightened condition-dependent expression as predicted by the handicap hypothesis? Proc. $R$. Soc. Lond. B 271: 771-783.

Cuervo, J.J., Lope, F. \& Møller, A.P. 1996. The function of long tails in female barn swallows (Hirundo rustica): an experimental study. Behav. Ecol. 7: 132-136.

Dale, J. 2006. Intraspecific variation in coloration. In: Bird Coloration. Vol. 2 (G.E. Hill \& K.J. McGraw, eds), pp. 36-86. Harvard University Press, Cambridge, MA.
Darwin, C. 1871. The Descent of Man, and Selection in Relation to Sex. Murray, London.

Dey, C.J., Jamieson, I.C. \& Quinn, J.S. 2012. Reproductive skew and female trait elaboration in a cooperatively breeding rail. Ibis 154: 452-460.

Doutrelant, C., Grégoire, A., Grnac, N., Gómez, D., Lambrechts, M.M. \& Perret, P. 2008. Female coloration indicates female reproductive capacity in blue tits. J. Evol. Biol. 21: 226-233.

Doutrelant, C., Grégoire, A., Midamegbe, A., Lambrechts, M. $\delta$ Perret, P. 2012. Female plumage coloration is sensitive to the cost of reproduction. An experiment in blue tits. J. Anim. Ecol. 81: 87-96.

Ezenwa, V.O. \& Jolles, A.E. 2008. Horns honestly advertise parasite infection in male and female African buffalo. Anim. Behav. 75: 2013-2021.

Falconer, D.S. \& MacKay, T.F.C. 1996. Introduction to Quantitative Genetics, 4th edn. Longmann, London.

Fitzpatrick, S., Berglund, A. \& Rosenqvist, G. 1995. Ornaments or offspring: costs to reproductive success restrict sexual selection processes. Biol. J. Linn. Soc. 55: 251-260.

Folstad, I. \& Karter, A.J. 1992. Parasites, bright males, and the immunocompetence handicap. Am. Nat. 139: 603-622.

Gasparini, J., Bize, P., Piault, R., Wakamatsu, K., Blount, J.D., Ducrest, A.-L. et al. 2009. Strength and cost of an induced immune response are associated with a heritable melaninbased colour trait in female tawny owls. J. Anim. Ecol. 78: 608-616.

Götmark, F., Post, P., Olsson, J. \& Himmelmann, D. 1997. Natural selection and sexual dimorphism: sex-biased sparrowhawk predation favours crypsis in female chaffinches. Oikos 80: 540-548.

Grafen, A. 1990. Biological signals as handicaps. J. Theor. Biol. 144: $517-546$.

Griggio, M., Valera, F., Casas, A. \& Pilastro, A. 2005. Males prefer ornamented females: a field experiment of male choice in the rock sparrow. Anim. Behav. 69: 1243-1250.

Griggio, M., Zanollo, V. \& Hoi, H. 2010. Female ornamentation, parental quality, and competitive ability in the rock sparrow. J. Ethol. 28: 455-462.

Gustafsson, L. \& Pärt, T. 1990. Acceleration of senescence in the collared flycatcher Ficedula albicollis by reproductive costs. Nature 347: 279-281.

Gustafsson, L., Qvarnström, A. \& Sheldon, B.C. 1995. Tradeoffs between life-history traits and a secondary sexual character in male collared flycatchers. Nature 375: 311313.

Hegyi, G., Rosivall, B. \& Török, J. 2006. Paternal age and offspring growth: separating the intrinsic quality of young from rearing effects. Behav. Ecol. Sociobiol. 60: 672-682.

Hegyi, G., Garamszegi, L.Z., Eens, M. \& Török, J. 2008. Female ornamentation and territorial conflict in collared flycatchers (Ficedula albicollis). Naturwissenschaften 95: 993996.

de Heij, M.E., Gustafsson, L. \& Brommer, J.E. 2011. Experimental manipulation shows that the white wing patch in collared flycatchers is a male sexual ornament. Ecol. Evol. 1: 546-555.

Jawor, J.M., Gray, N., Beall, S.M. \& Breitwisch, R. 2004. Multiple ornaments correlate with aspects of condition and behaviour in female northern cardinals, Cardinalis cardinalis. Anim. Behav. 67: 875-882. 
Kekäläinen, J., Huuskonen, H., Tuomaala, M. \& Kortet, R. 2010. Both male and female sexual ornaments reflect offspring performance in a fish. Evolution 64: 3149-3157.

Khila, A., Abouheif, E. \& Rowe, L. 2012. Function, developmental genetics, and fitness consequences of a sexually antagonistic trait. Science 336: 585-589.

Kraaijeveld, K., Kraaijeveld-Smit, F.J.L. \& Komdeur, J. 2007. The evolution of mutual ornamentation. Anim. Behav. 74: 657-677.

Lande, R. 1980. Sexual dimorphism, sexual selection and adaptation in polygenic characters. Evolution 34: 292-305.

Lande, R. 1987. Genetic correlations between the sexes in the evolution of sexual dimorphism and mating preferences. In: Sexual Selection: Testing the Alternatives (J.W. Bradbury $\delta$ M.B. Andersson, eds), pp. 83-95. Wiley, Chichester.

LeBas, N.R. 2006. Female finery is not for males. Trends Ecol. Evol. 21: 170-173.

Lebreton, J.-D. \& Pradel, R. 2002. Multistate recapture models: modelling incomplete individual histories. J. Appl. Stat. 29: 353-369.

Lebreton, J.-D., Burnham, K.P., Clobert, J. \& Anderson, D.R. 1992. Modeling survival and testing biological hypotheses using marked animals: a unified approach with case studies. Ecol. Monogr. 62: 67-118.

Lehtonen, P.K., Laaksonen, T., Artemyev, A.V., Belskii, E., Both, C., Bureš, S. et al. 2009. Geographic patterns of genetic differentiation and plumage colour variation are different in the pied flycatcher (Ficedula hypoleuca). Mol. Ecol. 18: 44634476.

Lehtonen, P.K., Laaksonen, T., Artemyev, A.V., Belskii, E., Berg, P.R., Both, C. et al. 2012. Candidate genes for colour and vision exhibit signals of selection across the pied flycatcher (Ficedula hypoleuca) breeding range. Heredity 108: 431-440.

Lundberg, A. \& Alatalo, R.V. 1992. The Pied Flycatcher. Poyser, London.

Martínez-Padilla, J., Vergara, P., Pérez-Rodríguez, L., Mougeot, F., Casas, F., Ludwig, S.C. et al. 2011. Condition- and parasite-dependent expression of a male-like trait in a female bird. Biol. Lett. 7: 364-367.

Massaro, M., Davis, L.S. \& Darby, J.T. 2003. Carotenoidderived ornaments reflect parental quality in male and female yellow-eyed penguins (Megadyptes antipodes). Behav. Ecol. Sociobiol. 55: 169-175.

McGraw, K.J., Adkins-Regan, E. \& Parker, R.S. 2005. Maternally derived carotenoid pigments affect offspring survival, sex ratio, and sexual attractiveness in a colorful songbird. Naturwissenschaften 92: 375-380.

Midamegbe, A., Grégoire, A., Perret, P. \& Doutrelant, C. 2011. Female-female aggressiveness is influenced by female coloration in blue tits. Anim. Behav. 82: 245-253.

Mills, S.C., Koskela, E. \& Mappes, T. 2012. Intralocus sexual conflict for fitness: sexually antagonistic alleles for testosterone. Proc. R. Soc. Lond. B 279: 1889-1895.

Morales, J., Moreno, J., Merino, S., Sanz, J.J., Tomás, G., Arriero, E. et al. 2007. Female ornaments in the Pied Flycatcher Ficedula hypoleuca: associations with age, health and reproductive success. Ibis 149: 245-254.

Morales, J., Velando, A. \& Torres, R. 2009. Fecundity compromises attractiveness when pigments are scarce. Behav. Ecol. 20: 117-123.
Moreno, J., Velando, A., Ruiz-de-Castañeda, R., GonzálezBraojos, S. \& Cantarero, A. 2012. Oxidative damage in relation to a female plumage badge: evidence for signalling costs. Acta Ethol. doi: 10.1007/s10211-012-0138-9.

Murphy, T.G., Rosenthal, M.F., Montgomerie, R. \& Tarvin, K.A. 2009. Female American goldfinches use carotenoidbased bill colouration to signal status. Behav. Ecol. 20: 1348-1355.

Nadeau, N.J., Burke, T. \& Mundy, N.I. 2007. Evolution of an avian pigmentation gene correlates with a measure of sexual selection. Proc. R. Soc. Lond. B 274: 1807-1813.

Newton, I. 1989. Lifetime Reproduction in Birds. Academic Press, London.

Nichols, J.D. \& Kendall, W.L. 1995. The use of multistate capture-recapture models to address questions in evolutionary ecology. J. Appl. Stat. 22: 835-846.

Orrell, M. \& Belda, E.J. 2002. Delayed cost of reproduction and senescence in the willow tit Parus montanus. J. Anim. Ecol. 71: 55-64.

Owens, I.P.F., Burke, T. \& Thompson, D.B.A. 1994. Extraordinary sex roles in the Eurasian Dotterel: female mating arenas, female-female competition, and female mate choice. Am. Nat. 144: 76-100.

Pärt, T. \& Qvärnstrom, A. 1997. Badge size in collared flycatchers predicts outcome of male competition over territories. Anim. Behav. 54: 893-899.

van de Pol, M. \& Verhulst, S. 2006. Age-dependent traits: a new statistical model to separate within- and betweenindividual effects. Am. Nat. 167: 766-773.

Potti, J. 1993. A male trait expressed in female pied flycatchers Ficedula hypoleuca: the white forehead patch. Anim. Behav. 45: 1245-1247.

Potti, J. 2000. Causes and consequences of age-assortative pairing in Pied Flycatchers (Ficedula hypoleuca). Etología 8: 29-36.

Potti, J. \& Canal, D. 2011 . Heritability and genetic correlation between the sexes in a songbird sexual ornament. Heredity 106: $945-954$.

Potti, J. \& Merino, S. 1996. Decreased levels of blood trypanosome infection correlate with female expression of a male secondary sexual trait: implications for sexual selection. Proc. R. Soc. Lond. B 263: 1199-1204.

Potti, J. \& Montalvo, S. 1991a. Male arrival and female mate choice in pied flycatchers Ficedula hypoleuca in central Spain. Ornis Scand. 22: 45-54.

Potti, J. \& Montalvo, S. 1991b. Return rate, age at first breeding and natal dispersal of pied flycatchers Ficedula hypoleuca in Central Spain. Ardea 79: 449-458.

Potti, J. \& Montalvo, S. 1993. Polygyny in Spanish pied flycatchers Ficedula hypoleuca. Bird Study 40: 31-37.

Pradel, R., Wintrebert, C.M.A. \& Gimenez, O. 2003. A proposal for a goodness-of-fit test to the Arnason-Schwarz multisite capture-recapture model. Biometrics 59: 43-53.

Price, T. 1998. Maternal and paternal effects in birds. In: Maternal Effects as Adaptations (T.A. Mousseau \& C.W. Fox, eds), pp. 202-226. Oxford University Press, Oxford.

Pryke, S.R. 2007. Fiery red heads: female dominance among head color morphs in the Gouldian finch. Behav. Ecol. 18: 621-627.

Qvarnström, A., Brommer, J.E. \& Gustafsson, L. 2006. Testing the genetics underlying the co-evolution of mate choice and ornament in the wild. Nature 441: 84-86. 
Robinson, M.R. \& Kruuk, L.E.B. 2007. Function of weaponry in females: the use of horns in intrasexual competition for resources in female Soay sheep. Biol. Lett. 22: 651-654.

Robinson, M.R., Pilkington, J.G., Clutton-Brock, T.H., Pemberton, J.M. \& Kruuk, L.E.B. 2006. Live fast, die young: trade-offs between fitness components and sexually antagonistic selection on weaponry in Soay sheep. Evolution 60: $2168-2181$.

Rosvall, K.A. 2011. Intrasexual competition in females: evidence for sexual selection? Behav. Ecol. 22: 1131-1140.

Roulin, A. 1999. Nonrandom pairing by male barn owls (Tyto alba) with respect to a female plumage trait. Behav. Ecol. 6: 688-695.

Roulin, A. 2004. The evolution, maintenance and adaptive function of genetic colour polymorphism in birds. Biol. Rev. 79: 815-848.

Roulin, A., Richner, H. \& Ducrest, A.-L. 1998. Genetic, environmental, and condition-dependent effects on female and male ornamentation in the barn owl Tyto alba. Evolution 52 : $1451-1460$.

Roulin, A., Jungi, T.V., Pfister, H. \& Dijkstra, C. 2000. Female barn owls (Tyto alba) advertise good genes. Proc. R. Soc. Lond. B 267: 937-941.

Roulin, A., Dijkstra, C., Riols, C. \& Ducrest, A.L. 2001 la. Female and male-specific signals of quality in the barn owl. J. Evol. Biol. 14: 255-266.

Roulin, A., Riols, C., Dijkstra, C. \& Ducrest, A.L. $2001 \mathrm{~b}$ Female plumage spottiness signals parasite resistance in the barn owl (Tyto alba). Behav. Ecol. 12: 103-110.

Roulin, A., Altwegg, R., Jensen, H., Steinsland, I. \& Schaub, M. 2010. Sex-dependent selection on an autosomal melanic female ornament promotes the evolution of sex ratio bias. Ecol. Lett. 13: 616-626.

Roulin, A., Antoniazza, S. \& Burri, R. 2011. Spatial variation in the temporal change of male and female melanic ornamentation in the barn owl. J. Evol. Biol. 24: 1403-1409.

SAS Institute Inc. 2008. SAS/STAT® 9.2 User's Guide: The GLIMMIX Procedure (Book Excerpt). SAS Institute Inc, Cary, NC.

Seber, G.A.F. 1982. The Estimation of Animal Abundance and Related Parameters. Blackburn Press, Caldwell, NJ.

Sheldon, B.C. \& Ellegren, H. 1999. Sexual selection resulting from extrapair paternity in collared flycatchers. Anim. Behav. 57: $285-298$.

Siefferman, L. \& Hill, G.E. 2005. Evidence for sexual selection on structural plumage coloration in female eastern bluebirds (Sialia sialis). Evolution 59: 1819-1828.

Simmons, L.W. \& Emlen, D.J. 2008. No fecundity cost of female secondary sexual trait expression in the horned beetle Onthophagus sagittarius. J. Evol. Biol. 21: 1227-1235.

Stockley, P. \& Bro-Jørgensen, J. 2010. Female competition and its evolutionary consequences in mammals. Biol. Rev. 86: 341-366.

Swaddle, J.P. \& Witter, M.S. 1995. Chest plumage, dominance and fluctuating asymmetry in female starlings. Proc. R. Soc. Lond. B 260: 219-223.
Tella, J.L., Forero, M.G., Donázar, J.A. \& Hiraldo, F. 1997. Is the expression of male traits in female lesser kestrels related to sexual selection? Ethology 103: 72-81.

Tobias, A., Montgomerie, R. \& Lyon, B.E. 2012. The evolution of female ornaments and weaponry: social selection, sexual selection and ecological competition. Philos. Trans. $R$ Soc. Lond. B Biol. Sci. 367: 2274-2293.

Velando, A., Lessells, C.M. \& Márquez, J.C. 2001. The function of female and male ornaments in the Inca tern: evidence for links between ornament expression and both adult condition and reproductive performance. J. Avian Biol. 32: $311-318$.

Vergara, P., Fargallo, J.A., Martínez-Padilla, J. \& Lemus, J.A. 2009. Inter-annual variation and information content of melanin-based colouration in female Eurasian kestrels. Biol. J. Linn. Soc. 97: 781-790.

Weiss, S.L. 2006. Female-specific color is a signal of quality in the striped plateau lizard (Sceloporus virgatus). Behav. Ecol. 17: 726-732.

White, G.C. \& Burnham, K.P. 1999. Program MARK: survival estimation from populations of marked animals. Bird Study 46: 120-139.

Williams, T.M. \& Carroll, S.B. 2009. Genetic and molecular insights into the development and evolution of sexual dimorphism. Nat. Rev. Genet. 10: 797-804.

Wilson, A.J. \& Nussey, D.H. 2009. What is individual quality? An evolutionary perspective. Trends Ecol. Evol. 25: 207-214.

Wright, D., Kerge, S., Brändström, H., Schütz, K., Kindmark, A., Andersson, L. et al. 2007. The genetic architecture of a female sexual ornament. Evolution 62: 86-98.

Zahavi, A. 1975. Mate selection - a selection for a handicap. J. Theor. Biol. 53: 205-214.

\section{Supporting information}

Additional Supporting Information may be found in the online version of this article:

Table S1 GLMMs (final models) showing the effects of female age and forehead patch expression on (a) yearly numbers of young fledged (Poisson distribution); (b) yearly numbers of recruits (negbin distribution).

Table S2 GLMMs (final models) showing the effects of female age and forehead patch expression on (a) total (lifetime) numbers of young fledged (Poisson distribution); (b) total (lifetime) numbers of recruits (negbin distribution) after controlling for longevity and age of first reproduction.

Data deposited at Dryad: doi: 10.5061/dryad.ff52k 